\title{
The Characterization of Linear Polyethylene SRM 1475. I. Introduction.
}

\author{
C. A. J. Hoeve, ${ }^{*}$ Herman I.. Wagner, and Peter H. Verdier \\ Institute for Materials Research, National Bureau of Standards, Washington, D.C. 20234
}

(December 15, 1971)

\begin{abstract}
The National Bureau of Standards has issued a linear polyethylene standard reference material, SRM 1475. In this report a general description of the sample is given, and the characterization work described in the subsequent reports is outlined. Some pellet-to-pellet variability was found and estimated.
\end{abstract}

Key words: Fractionation; linear polyethylene; molecular weight; molecular weight distribution; National Bureau of Standards; pellet variability; standard reference material.

\section{Purpose}

The National Bureau of Standards has issued a linear polyethylene standard reference material, SRM $1475,{ }^{* *}$ to fill the need for a well-characterized sample of this polymer. The sample may be used for the calibration of instruments for measuring molecular weight and molecular weight distribution, such as light scattering photometers and gel permeation chromatographs. It should also be useful in other areas of polymer research such as dilute solution studies, polymer rheology, and polymer crystal physics.

\section{Properties Measured}

The characterization results which are described in the succeeding papers in this series $[1]^{1}$ include a determination of:

(1) Weight average molecular weight by light scattering,

(2) molecular weight distribution by gel permeation chromatography and, from this distribution, weight average, number average, and $\mathrm{Z}$ average molecular weights,

(3) limiting viscosity number in 1-chloronaphthalene, 1,2,4-trichlorobenzene, and decalin,

(4) melt flow rate by a melt index type apparatus,

(5) density by ASTM procedures.

No attempt was made to determine number average molecular weight of this whole polymer by osmometry

*Present address: Department of Chemistry, Texas A \& M University, College Station, Texas 77843 .

**Available through the Office of Standard Reference Materials, National Bureau of Standards, Washington, D.C. 20234.

${ }^{1}$ Figures in brackets indicate the literature references at the end of this paper. since diffusion of even small amounts of low molecular weight species through the membrane makes such a determination meaningless. However, by calibration of the gel permeation chromatograph with fractions that were well characterized by light scattering and osmometry, it was possible to determine number average molecular weight as well as weight average and molecular weight distribution. With these data, SRM 1475 may be used conveniently for the precise calibration of other gel permeation chromatographs.

In the papers which follow, the various techniques are described. More detail is given in those cases where there has been some deviation from the usual procedure. The certificate for SRM 1475 is reproduced at the end of this paper.

\section{Sample Description}

The sample of linear polyethylene chosen for SRM 1475, an ALATHON 7050, was kindly donated by the E. I. duPont Company, Wilmington, Delaware.* The material is in the form of pellets, each weighing about $20 \mathrm{mg}$. An antioxidant, tetrakis [methylene-3- $\left(3^{\prime}, 5^{\prime}\right.$-di$t$-butyl-4'-hydroxyphenyl)propionate]methane, known commonly as Irganox 1010 (Geigy Chemical Company), was added to the polymer at a concentration of 111 ppm by the manufacturer. The linearity of the polymer is demonstrated, as shown in part II [1], by infrared analysis. Ash content, determined by ashing a 10gram portion of the sample at $750{ }^{\circ} \mathrm{C}$, was found to be 0.002 percent.

\footnotetext{
* Certain commercial equipment, instruments, or materials are identified in this paper in order to adequately specify the experimental procedure. In no case does such identification imply recommendation or endorsement by the National Bureau of Standards, nor does it imply that the material or equipment identified is necessarily the best available for the purpose.
} 
The determination of volatile components, or at least those components soluble in xylene, was made as follows. Three grams of polyethylene and 7 grams of xylene were sealed in one container and 7 grams of xylene was sealed in another as a control. These containers were heated at $140{ }^{\circ} \mathrm{C}$ until the contents dissolved. They were cooled to precipitate the polyethylene, opened, and samples of liquid from each were analyzed by gas chromatography.

It is estimated that any xylene-soluble volatiles that amounted to as much as $1 / 2$ percent of the polyethylene could be readily detected by this method. No evidence of such volatile material was found.

\section{Sampling}

The sample was received in forty 50 -lb bags. To determine the conditions necessary for uniform sampling, polymer variability from pellet-to-pellet and bagto-bag was determined. The bags were numbered at random from 1 to 40 and samples were taken from the top and bottom of each of bags 1 to 20. Several grams of each of these were mixed and samples drawn from this "pool" to make up blended samples for iight scattering, limiting viscosity number, and gel permeation chromatography. These blends were made up of several hundred pellets dissolved in xylene at $140{ }^{\circ} \mathrm{C}$ and precipitated in ethanol at room temperature.

Pellet-to-pellet variability was determined by solution viscosity measurements [1d] in 1-chloronaphthalene at concentrations of from 0.06 to $0.12 \mathrm{~g} / \mathrm{dl}$ at $130{ }^{\circ} \mathrm{C}$ on individual pellets and on samples of the blends. The viscosity number, $\left(\eta-\eta_{0}\right) /\left(\eta_{0} c\right)$, in $\mathrm{dl} / \mathrm{g}$, where $\eta$ is the viscosity of the solution, $\eta_{0}$ is the viscosity of the solvent, and $c$ is the concentration in $\mathrm{g} / \mathrm{dl}$, is plotted against concentration in figure 1. The viscosity numbers obtained for the blended samples were fitted by least squares to a linear function of concentration, yielding the straight line shown in the figure. The standard deviation in viscosity number obtained from the least-squares analysis for the blended samples was $0.0034 \mathrm{dl} / \mathrm{g}(0.38 \%)$. The rootmean-square deviation from the straight line of the viscosity numbers obtained for solutions made up from individual pellets was found to be $0.028 \mathrm{dl} / \mathrm{g}(3.1 \%)$. Thus the standard deviation of a single measurement is 0.38 percent and the standard deviation due to pellet-to-pellet variation is

$$
\left[(3.1)^{2}-(0.38)^{2}\right]^{1 / 2}=3.1 \% .
$$

Since the coefficient of variation is 3 percent, it is recommended that all determinations be performed on samples containing at least 50 pellets or one gram of polymer (or material from a blend of one gram). This will reduce the expectation of the standard error due to pellet variability to less than 0.5 percent.

Details of the method of measurement of melt flow rate and the results obtained are discussed elsewhere [1c]. These measurements were employed to investigate variations in material taken from different regions of the entire material. Forty-two samples for

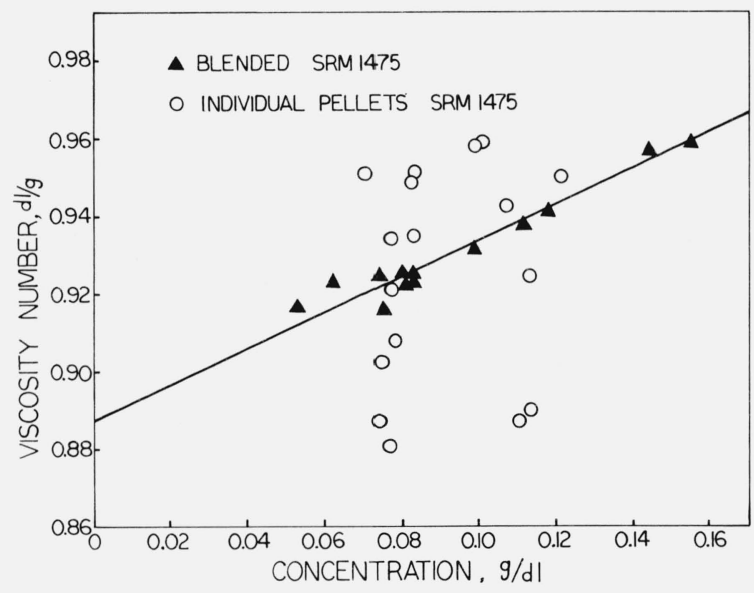

FIGURE 1. The viscosity number of a blended sample and of individual pellets of SRM 1475 plotted against concentration.

melt flow rate determination were taken from 13 different regions in seven of the bags. The standard deviation for samples within a region was found to be 2.1 percent, based on 29 degrees of freedom. The standard deviation between regions was found to be 1.7 percent, based on 12 degrees of freedom. We conclude that variations from region to region are too small to be detected by this method.

\section{References}

[1] The Characterization of Linear Polyethylene 1475:

(a) Brown, J. E., Paper II, Determination of Total Methyl Content by Infrared Spectrophotometry, J. Res. Nat. Bur. Stand. (U.S.), 76A (Phys. and Chem.), No. 2, 141-142 (Mar-Apr. 1972).

(b) Brown, J. E., Paper III, Density Determination, Ibid, 76A (Phys. and Chem.), No. 2, 143-144 (Mar--Apr. 1972).

(c) Maurey, J. R., Paper IV, Melt Flow Rate, Ibid, 76A (Phys. and Chem.), No. 2, 145-146 (Mar.-Apr. 1972).

(d) Christensen, R. G., Paper V, Solution Viscosity Measurements, Ibid, 76A (Phys. and Chem.), No. 2, 147-149 (MarApr. 1972).

(e) Christensen, R. G., Paper VI, Preparation of Calibrating Fractions, Ibid, 76A (Phys. and Chem.), No. 2, 149-150 (Mar-Apr. 1972).

(f) Wagner, H. L., Paper VII, Differential Refractive Index of Polyethylene Solutions, Ibid, 76A (Phys. and Chem.), No. 2, 151-155 (Mar--Apr. 1972).

(g) Frolen, L. J., Ross, G. S., Wims, A. M., and Verdier, P. H., Paper VIII, Light Scattering Studies on Polyethylenes in 1-Chloronaphthalene, Ibid, 76A (Phys. and Chem.), No. 2, 156-160 (Mar.-Apr. 1972).

(h) Brown, J. E., and Verdier, P. H., Paper IX, Number Average Molecular Weight of Fractions by Membrane Osmometry, Ibid, 76A (Phys. and Chem.), No. 2, 161-163 (Mar.-Apr. 1972).

(i) Ross, G. S. and Frolen, L. J., Paper X, Gel Permeation Chromatography, Ibid, 76A (Phys. and Chem.), No. 2, 163170 (Mar.-Apr. 1972).

(Paper 76A2-706) 


\title{
Standard Reference Material 1475
}

\author{
Linear Polyethylene \\ (Whole Polymer)
}

\author{
C. A. J. Hoeve, H. L. Wagner, J. E. Brown, \\ R. G. Christensen, L. J. Frolen, J. R. Maurey, G. S. Ross, and P. H. Verdier
}

This Standard Reference Material is intended for the calibration of instruments used in polymer science and technology for the determination of molecular weight and molecular weight distribution.

\section{Quantity}

Molecular Weight

Weight-average molecular weight $\mathrm{t}^{\mathrm{a}}$

Number-average molecular weight

Weight-average molecular weight

$\mathrm{Z}$-average molecular weight

Ratio of molecular weights $\mathrm{M}_{\mathrm{z}}: \mathrm{M}_{\mathrm{w}}: \mathrm{M}_{\mathrm{n}}$

Molecular weight distribution

Limiting Viscosity Number ( $\mathrm{dl} / \mathrm{g})$

In 1-chloronaphthalene at $130^{\circ} \mathrm{C}$

In $1,2,4$-trichlorobenzene at $130^{\circ} \mathrm{C}$

In decahydronaphthalene $e^{\mathrm{c}}$ at $130^{\circ} \mathrm{C}$

Melt-Flow Rate $(\mathrm{g} / 10 \mathrm{~min})^{\mathrm{d}}$

Density $\left(\mathrm{g} / \mathrm{cm}^{3}\right)^{\mathrm{e}}$

\section{Average \\ Values}

52,000

18,310

53,070

138,000

7.54:2.90:1
Estimated Standard Deviation of Average

2,000

\section{0}

620

3,700

See Table 1

$\begin{array}{rr}0.890 & 0.0032 \\ 1.010 & .0086 \\ 1.180 & .0032 \\ & \\ 2.07 & .0062\end{array}$

0.97844

.00004

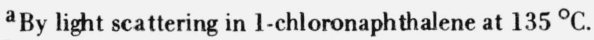

bBy gel-permeation chromatography.

c "Technical" grade, which assayed at approximately equal proportions of cis- and trans- decahydronaphthalenes.

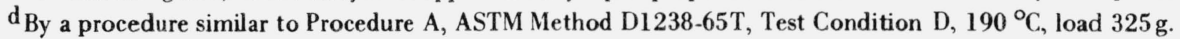

${ }^{\mathrm{e}}$ By ASTM Method D1505-67; sample prepared by Procedure A, ASTM Method D1928-68.

Measurements leading to the certification of this material were performed in the Molecular Properties and Characterization Section of the Polymer Division.

Washington, D.C. 20234

November 6, 1969

(Revised December 2, 1971)
J. Paul Cali, Chief

Office of Standard Reference Materials 
The methyl group content as determined by ASTM Method D2238-68 is 0.15 methyl groups per 100 carbon atoms. This shows the polyethylene to be essentially linear. A pellet to pellet coefficient of variation of 3 percent in the limiting viscosity number was found. All determinations should consequently be performed on samples containing at least 50 pellets or one gram of polymer (or material from a blend of one gram). This will reduce the expectation of the standard error due to pellet variability to less than 0.5 percent.

Table 1. Cumulative Molecular Weight Distribution by Gel-Permeation Chromatography

$\begin{array}{llllll}\log \mathrm{M} & \begin{array}{c}\text { Wt. } \\ \%\end{array} & \log \mathrm{M} & \begin{array}{c}\text { Wt. } \\ \%\end{array} & \log \mathrm{M} & \begin{array}{c}\text { Wt. } \\ \%\end{array} \\ 2.800 & 0.0 & 4.014 & 15.2 & 5.065 & 90.7 \\ 2.865 & 0.005 & 4.070 & 18.1 & 5.113 & 92.2 \\ 2.929 & 0.020 & 4.126 & 21.5 & 5.161 & 93.7 \\ 2.992 & 0.052 & 4.182 & 25.2 & 5.209 & 94.8 \\ 3.056 & 0.105 & 4.237 & 29.3 & 5.256 & 95.8 \\ & & & & & \\ 3.119 & 0.185 & 4.292 & 33.7 & 5.303 & 96.6 \\ 3.181 & 0.343 & 4.346 & 38.5 & 5.349 & 97.3 \\ 3.243 & 0.475 & 4.400 & 43.4 & 5.395 & 97.9 \\ 3.305 & 0.706 & 4.454 & 48.5 & 5.440 & 98.4 \\ 3.366 & 0.999 & 4.507 & 53.5 & 5.485 & 98.7 \\ 3.427 & 1.38 & 4.560 & 58.3 & & \\ 3.488 & 1.88 & 4.612 & 62.9 & 5.530 & 99.1 \\ 3.548 & 2.51 & 4.664 & 67.3 & 5.618 & 99.3 \\ 3.607 & 3.30 & 4.715 & 71.4 & 5.662 & 99.7 \\ 3.667 & 4.28 & 4.766 & 75.1 & 5.705 & 99.8 \\ 3.725 & 5.46 & & & & \\ 3.784 & 6.87 & 4.817 & 78.5 & 5.789 & 99.9 \\ 3.842 & 8.56 & 4.868 & 81.6 & 5.87 & 100.0 \\ 3.900 & 10.50 & 4.918 & 84.4 & & \\ 3.957 & 12.7 & 4.967 & 86.7 & & \end{array}$

The sample of linear polyethylene was obtained from E. I. du Pont de Nemours and Company of Wilmington, Delaware.

This sample of linear polyethylene has an ash content of 0.002 percent. No volatiles were detected by a gas-chromatographic procedure capable of detecting 0.5 percent volatiles. The manufacturer added $111 \mathrm{ppm}$ of the antioxidant, Irganox 1010 (Geigy), which is tetrakis [methylene3-(3',5'-di-t-butyl-4' -hydroxyphenyl)propionate] methane.

The differential refractive index in 1-chloronaphthalene, required for the calculation of molecular weight by light scattering, was found to be $-0.193 \mathrm{ml} / \mathrm{g}$ at $135^{\circ} \mathrm{C}$ and $546 \mathrm{~nm}$.

The maximum rate of shear in the Ubbelohde viscometer was about $1500 \mathrm{sec}^{-1}$. All measurements were carried out at specific viscosities ( 0.1 or less) which were sufficiently low for negligible dependence on rate of shear.

A series of reports describing investigations required for this certificate will be published in the Journal of Research of the National Bureau of Standards, Volume 76 A, No. 2, 1972. 